\title{
Conserving relics from ancient underground worlds: Assessing the influence of cave and landscape features on obligate iron cave dwellers from the Eastern Amazon
}

\author{
Rodolfo Jaffé ${ }^{\text {Corresp., }}$ 1, 2, 3 , Xavier Prous ${ }^{4}$, Allan Calux ${ }^{4}$, Markus Gastauer ${ }^{1}$, Gilberto Nicacio $^{1}$, Robson \\ Zampaulo $^{4}$ ， Pedro W.M. Souza-Filho ${ }^{1,5}{ }^{\text {, Guilherme Oliveira }}{ }^{1}$ ， Iuri V Brandi ${ }^{4}$ ， José O Siqueira ${ }^{1}$ \\ 1 Instituto Tecnológico Vale, Belém, PA, Brazil \\ 2 Ecology, Universidade de São Paulo, São Paulo, São Paulo, Brazil \\ 3 Ecology, Universidade Federal do Pará, Belém, Pará, Brazil \\ 4 Environmental Licensing and Speleology, Vale, Nova Lima, Minas Gerais, Brazil \\ 5 Geoscience, Universidade Federal do Pará, Belém, Pará, Brazil \\ Corresponding Author: Rodolfo Jaffé \\ Email address: r.jaffe@ib.usp.br
}

The degradation of subterranean habitats is believed to represent a serious threat for the conservation of obligate subterranean dwellers (troglobites), many of which are shortrange endemics. However, while the factors influencing cave biodiversity remain largely unknown, the influence of the surrounding landscape and patterns of subterranean connectivity of terrestrial troglobitic communities have never been systematically assessed. Using spatial statistics to analyze the most comprehensive speleological database yet available for tropical caves, we first assess the influence of iron cave characteristics and the surrounding landscape on troglobitic communities from the Eastern Amazon. We then determine the spatial pattern of troglobitic community composition, species richness, phylogenetic diversity, and the occurrence of frequent troglobitic species, and finally quantify how different landscape features influence the connectivity between caves. Our results reveal the key importance of habitat amount, guano, water, lithology, geomorphology, and elevation in shaping iron cave troglobitic communities. While mining within $250 \mathrm{~m}$ from the caves influenced species composition, increasing agricultural land cover within $50 \mathrm{~m}$ from the caves reduced species richness and phylogenetic diversity. Troglobitic species composition, species richness, phylogenetic diversity, and the occurrence of frequent troglobites showed spatial autocorrelation for up to $40 \mathrm{~km}$. Finally, our results suggest that the conservation of cave clusters should be prioritized, as geographic distance was the main factor determining connectivity between troglobitic communities. Overall, our work sheds important light onto one of the most overlooked terrestrial ecosystems, and highlights the need to shift conservation efforts from individual caves to subterranean habitats as a whole. 
1 Conserving relics from ancient underground worlds: Assessing the

2 influence of cave and landscape features on obligate iron cave

3 dwellers from the Eastern Amazon

4 Rodolfo Jaffé ${ }^{1,2,3 *}$, Xavier Prous ${ }^{4}$, Allan Calux ${ }^{4}$, Markus Gastauer ${ }^{1}$, Gilberto Nicacio ${ }^{1}$, Robson

5 Zampaulo $^{4}$, Pedro Walfir M. Souza-Filho ${ }^{1,5}$, Guilherme Oliveira ${ }^{1}$, Iuri Viana Brandi ${ }^{4}$, José

6 Oswaldo Siqueira ${ }^{1}$

$7 \quad{ }^{1}$ Instituto Tecnológico Vale, Belém-PA, Brazil.

$8 \quad{ }^{2}$ Universidade de São Paulo, Departamento de Ecologia, São Paulo-SP, Brazil.

$9 \quad{ }^{3}$ Universidade Federal do Pará, Instituto de Ciências Biológicas, Belém-PA, Brazil.

$10{ }^{4}$ Vale - Environmental Licensing and Speleology, Nova Lima-MG, Brazil.

$11{ }^{5}$ Universidade Federal do Pará - Geoscience Institute, Belém-PA, Brazil.

$12 *$ Corresponding author

13 Email: rodolfo.jaffe@,itv.org / Phone: +55 (91) 32135523 


\section{Abstract}

15 The degradation of subterranean habitats is believed to represent a serious threat for the

16 conservation of obligate subterranean dwellers (troglobites), many of which are short-range

17 endemics. However, while the factors influencing cave biodiversity remain largely unknown, the

18 influence of the surrounding landscape and patterns of subterranean connectivity of terrestrial

19 troglobitic communities have never been systematically assessed. Using spatial statistics to

20 analyze the most comprehensive speleological database yet available for tropical caves, we first assess the influence of iron cave characteristics and the surrounding landscape on troglobitic communities from the Eastern Amazon. We then determine the spatial pattern of troglobitic community composition, species richness, phylogenetic diversity, and the occurrence of frequent troglobitic species, and finally quantify how different landscape features influence the connectivity between caves. Our results reveal the key importance of habitat amount, guano, water, lithology, geomorphology, and elevation in shaping iron cave troglobitic communities. While mining within $250 \mathrm{~m}$ from the caves influenced species composition, increasing agricultural land cover within 50m from the caves reduced species richness and phylogenetic diversity. Troglobitic species composition, species richness, phylogenetic diversity, and the occurrence of frequent troglobites showed spatial autocorrelation for up to $40 \mathrm{~km}$. Finally, our results suggest that the conservation of cave clusters should be prioritized, as geographic distance was the main factor determining connectivity between troglobitic communities. Overall, our work sheds important light onto one of the most overlooked terrestrial ecosystems, and highlights the need to shift conservation efforts from individual caves to subterranean habitats as a whole. 


\section{Introduction}

Caves harbor a unique biodiversity, often comprising obligate subterranean dwellers which must complete their entire life cycle underground (also known as troglobites) (Pipan \& Culver, 2013). The unparalleled nature of subterranean environments has facilitated the evolution of many endemic troglobites, some of which are considered relics of ancient worlds because their closest relatives have long disappeared from surface environments (Culver \& Pipan, 2009; Juan et al., 2010). Many of these troglobitic species are considered short-range endemics (Harvey, 2002), because they have only been found in a few caves. As dispersal is assumed to be restricted in these organisms, the degradation of subterranean habitats is believed to represent a threat for the conservation of such short-range endemics. Rare troglobites have therefore been the primary targets of cave conservation efforts worldwide (Harvey et al., 2011; Wynne \& Voyles, 2013; Culver \& Pipan, 2014; Ferreira, Oliveira \& Silva, 2015).

Environmental protection agencies of many countries prioritize the conservation of threatened troglobites (Guzik et al., 2011; Harvey et al., 2011; Auler \& Piló, 2015), and require extensive speleological surveys prior to the implementation of mining and infrastructure projects. Brazil has one of the most stringent cave protection regimes in the world, which requires government agencies and consulting companies to categorize caves into one of four relevance categories (maximum, high, mid, or low), based on a complex set of biological, geological, and cultural attributes (Auler \& Piló, 2015). Such categorization is later checked by the environmental protection agencies. Caves containing rare endemic troglobitic species, for instance, are always defined as maximum relevance caves, which must be protected along with a buffer area of $250 \mathrm{~m}$ (Jaffé et al., 2016). High relevance caves, on the other hand, can be impacted if appropriate compensation offsets are provided (i.e. preserving two similar caves). Since this protection regime is strictly enforced, the protection of maximum and high relevance caves essentially directs large development projects such as mining operations (Fig. 1).

Whereas the factors influencing cave biodiversity remain largely unknown (Pipan \& Culver, 2013; Culver \& Pipan, 2014), and the impact of the surrounding landscape on terrestrial troglobitic communities has never been systematically assessed (Hutchison et al., 2016; Pellegrini et al., 2016). However, a recent study found that habitat (karst) amount and landscape rugosity can predict the presence of major faunal groups of cave obligate species (Christman et al., 2016). Previous studies have reported spatial autocorrelation in the number and occurrence frequency of troglobites (Christman et al., 2005; Jaffé et al., 2016), which suggests some level of subterranean dispersal through porous rocks or micro-cavities (Auler et al., 2014). However, the factors influencing subterranean connectivity remain unexplored. Knowledge gaps are even larger in the tropics, where most troglobites remain unidentified to the species level, their distribution ranges have been established based on limited sampling, and their dispersal mechanisms are yet to be determined (Trajano \& Bichuette, 2010; Auler \& Piló, 2015; Jaffé et al., 2016). For instance, of the 150 troglomorphic species known to be associated to Brazilian iron caves, only 10 have been formally described, and include spiders, isopods, springtails, beetles, true bugs and millipedes (Ferreira, Oliveira \& Silva, 2015).

Here we aim to fill some of these knowledge gaps taking advantage of the most comprehensive speleological database yet available for tropical caves. The Carajás mineral province (South-Eastern Amazon, Brazil) contains one of the world's largest deposits of highgrade iron ore (Poveromo, 1999) and some of the largest iron ore mining projects are operating in the region. The environmental licensing of these mines required extensive speleological surveys, 
80

81

82

83

84

85

86

87

88

89

90

91

92

93

94

95

96

97

98

99

100

101

102

103

104

105

106

107

108

109

110

111

112

113

114

115

116

117

118

119

120

undertaken by different companies during the past decade. These surveys generated a wealth of data on cave biodiversity and geological characteristics of iron caves, which not only contain higher richness of troglomorphic species than caves of other lithologies (Silva, Martins \& Ferreira, 2011), but are also amongst the most threatened subterranean ecosystems. The present study assesses how cave and landscape features influence community composition, species richness, phylogenetic diversity, occurrence and connectivity patterns using previously unpublished and throughly curated lists of troglobitic species for 473 iron caves. We hope the generated knowledge will help guide sound conservation efforts and achieve the best compromise between mining and the protection of cave biodiversity.

Specifically, our study aims to: 1) Assess the influence of cave characteristics and the surrounding landscape on troglobitic species composition, species richness, phylogenetic diversity, and the occurrence of frequent troglobitic species; 2) Determine the spatial pattern of troglobitic community composition, species richness, phylogenetic diversity, and the occurrence of frequent troglobitic species; and 3) Quantify how different landscape features influence the connectivity between caves.

\section{Materials \& Methods}

Jaffé et al. (2016) used data from 844 iron caves to assess how the current relevance classification scheme ranks caves with different biodiversity indicators. Additionally, they modelled total species richness (considering all taxa found inside caves), and the presence/absence of rare troglobites, troglobites and bat populations. In the present work we retrieved previously unpublished data from a curated database containing comprehensive lists of all troglobitic taxa occurring in 473 iron caves of Carajás, State of Pará, Brazil. We then use this dataset to assess the influence of cave characteristics and the surrounding landscape on troglobitic communities, model troglobitic community composition, troglobitic species richness, troglobitic phylogenetic diversity, and the occurrence of frequent troglobitic species, and finally quantify how different landscape features influence the connectivity between caves.

\section{Dataset}

Initially, species inventories were obtained from speleology reports prepared by independent consulting companies. All but one report (N5M2) have already been submitted to the corresponding government agencies (the Brazilian Environmental Protection Agency - IBAMA, and the Pará State's Environment Agency - SEMAS-PA), and are available as Supporting Information in Jaffé et al. (2016). Consulting companies employed similar sampling methods and evaluated the same set of cave attributes (as specified in the Brazilian legislation for the protection of caves: Federal Decree 6640/2008 and Normative Instruction MMA 02/2017). Cave terrestrial fauna, for instance, was surveyed through the full extension of each cave, once during the dry season and once during the wet season. Species lists were later validated by specialized taxonomists, who compared collected specimens across caves and identified them to the finest possible taxonomic level. Still, many specimens were left to the morpho-species level because they represent new undescribed taxa (Trajano \& Bichuette, 2010). Taxonomists classified species as troglobites if they exhibited troglomorphic traits (Pipan \& Culver, 2013) absent in phylogenetically related taxa occurring in above-ground habitats. Non-troglobitic species were 
121 not compared across caves so they were excluded from our dataset. Additionally, personnel from

122 the Department of Environmental Licensing and Speleology from Vale (a mining company),

123 traveled to caves containing rare troglobites to confirm occurrences and collect specimens in

124 surrounding caves, aiming at validating their occurrence range. We then gathered all available

125 information on the cave's characteristics from different speleology reports and Vale's speleology

126 database. These included cave coordinates, altitude, horizontal projection (length), slope, area,

127 volume, presence of percolating water and water reservoirs, presence of plant material, presence

128 of plant detritus, presence of roots, presence of guano, presence of other feces, presence of

129 regurgitation balls, presence of carcases, and presence of resident bat populations. We also

130 assessed the external environment by calculating additional cave and landscape metrics at four

131 different spatial scales $(50,100,250$, and 500m radii from the cave's centroid). These metrics

132 included subterranean area, cave density, cave declivity, lithology, distance to nearest creek,

133 geomorphology, and land cover (See Table S1). Water bodies and geomorphology maps were

134 obtained from the Brazilian Institute of Geography and Statistics (IBGE:

135 ftp://geoftp.ibge.gov.br/cartas e mapas/bases cartograficas continuas/bcim/), Souza-Filho et al.

136 (2016) provided a high resolution 2013 land cover map, and all other metrics were calculated

137 using data from Vale's speleology database. We could not retrieve all metrics in all caves, so

138 some were excluded from certain analyses. The full datasets, including the geographic

139 coordinates of all caves, can be found along with all R scripts as Supplemental Information

140 (Dataset S1). All statistical analyses were implemented in R (R Core, 2015).

\section{Modeling troglobitic species composition, species richness and phylogenetic diversity}

142 To avoid possible biases arising from unequal sampling efforts across caves, we only considered

143 presence/absence data, omitting abundance information. We first created a community matrix,

144 containing information on the presence or absence of a given species in each cave. We then used

145 the vegan R package (Oksanen et al., 2016) to run a Principal Coordinates Analysis (PCoA),

146 employing Bray-Curtis dissimilarity distances. The first two axis of this PCoA (MDS1 and

147 MDS2) were considered proxies of troglobitic community composition, and thus used as

148 response variables in subsequent composition models (Fig. S1). While troglobitic species

149 richness was estimated as the total number of species present in each cave, rarity-weighted

150 richness was also calculated to account for differences in species representation across caves

151 (Albuquerque \& Beier, 2015). Additionally, phylogenetic diversity was used as a proxy of

152 functional diversity (Flynn et al., 2011; Faith, 2015). We constructed a phylogenetic tree

153 containing all troglobitic families sampled in at least one cave using the Timetree of Life (Hedges

154 \& Kumar, 2009; Hedges et al., 2015). In its actual version, the Timetree of Life contains more

155 than 50000 species, and all families from our set of troglobitic species are represented. We

156 inserted genera and subsequently species this phylogeny, considering cases with more than two

157 genera per family or more than two species per genus as polytomies. The resulting phylogeny

158 was dated using the bladj algorithm from Phylocom-4.2 in combination with mean age estimates

159 of 29 internal nodes retrieved from the databases (Hedges \& Kumar, 2009; Hedges et al.,

160 2015) (Table S2). Nodes without age estimates were placed evenly between two dated nodes

161 (Fig. S2). Phylogenetic diversity was finally calculated for each cave using Phylocom 4.2 (Webb

162 et al., 2002), as the sum of the lengths of all branches considered members of the corresponding

163 minimum spanning path.

164 We assessed the influence of internal (cave characteristics) and external (surrounding 
165 landscape) features on our five response variables (species composition axes MDS1 and MDS2, 166 species richness, log-transformed rarity-weighted richness and phylogenetic diversity). To do so 167 we used the lme4 package (Bates et al., 2014) to fit linear mixed models (for species composition, 168 rarity-weighted richness and phylogenetic diversity) and generalized linear mixed models

169 (GLMM) with Poisson distributed errors (for species richness), always keeping the geological 170 unit (or highland) where the caves were located as a random effect. This allowed us to account 171 for spatial autocorrelation as well as other potential unmeasured site-specific covariates. We first 172 reduced the large number of initial predictor variables (see Table S1) by identifying the relevant 173 scale at which each landscape component best explained our five response variables. This was 174 done by comparing simple models containing the same predictor measured at the four different 175 spatial scales. Model selection was based on the Akaike Information Criterion (AIC), and the best 176 model (with the lowest AIC) was considered to represent the relevant scale for a given predictor. 177 Because lithology and geomorphology contained many different classes, we ran principal 178 component analyses for each group of variables and included the first two synthetic axis in our 179 models. We then fit full models containing predictors at the relevant scale for each response 180 variable, along with the largest possible number of uncorrelated covariates $(r<0.6)$. All models 181 contained more than 20 observations for every predictor variable, so overfitting was not an issue. 182 Likelihood ratio tests (LRT) were employed to compare full models with reduced models where 183 each predictor was removed one by one. Only predictor variables that significantly improved the 184 full model's log-likelihood (at $\alpha<0.05$ ) were included in the final best models. These were then

185 validated by plotting residual vs. fitted values, residual vs. predictors, and by looking at the 186 distribution of residuals. We also tested for spatial autocorrelation in the final model's residuals at 187 the minimum spatial scale (see below).

188 To assess sampling bias effects we tested if caves located in the proximity of mines (which influence mine planning) were sampled more or less intensively than more distant caves (which do not influence mine planning). To do so we modeled total species richness (all taxa recorded inside each cave), troglobitic species richness and presence of rare troglobites (found in three or less caves) in relation to the mining area surrounding caves at different spatial scales (distant caves had mining areas of zero). Different species richness and different probabilities of containing rare troglobites in caves surrounded by larger mining areas would indicate uneven sampling efforts (since more species are likely to have been identified and occurrence areas of rare species expanded with larger sampling efforts). On the contrary, similar richness and rarity patterns across all caves would reveal no systematic sampling bias effects. We ran GLMM with Poisson distributed errors (for species richness) and GLMM with Bernoulli distributed responses (for presence of rare troglobites), keeping the highland where the caves were located as a random effect. Since mining area surrounding the caves was correlated across spatial scales, we only constructed models containing a single predictor (mining area at a given scale).

\section{Modeling the occurrence of frequent troglobites}

203 To unravel which cave characteristics help predict the occurrence of certain troglobitic species we 204 analyzed a subset of our data containing the most frequent species (occurring in at least 30 205 caves). We decided not to analyze species occurring in fewer than 30 caves to avoid overfitting 206 and complete separation problems resulting from small sample sizes. The presence of each one of 207 these frequent species was modeled using generalized linear models with Bernoulli distributed 208 responses (logistic regressions). Presence/absence was thus set as response variable, and all 
209 meaningful uncorrelated cave attributes as predictors. As described above, LRT were employed to

210 identify which predictor variables improved the model's log-likelihood.

\section{1}

212

213

214

215

216

217

218

219

220

221

222

223

\section{Assessing spatial autocorrelation}

We assessed spatial autocorrelation in our five response variables (species composition axes MDS1 and MDS2, species richness, rarity-weighted richness and phylogenetic diversity). The package spdep (Bivand \& Piras, 2015) was employed to estimate Moran's I, a standard measure of spatial autocorrelation ranging from -1 (indicating perfect dispersion) to +1 (perfect correlation, with zero indicating a random spatial pattern). As Moran's I is affected by the spatial scale chosen to assign weights to neighbors, we quantified spatial autocorrelation across the full range of spatial scales of our data. We also tested for spatial autocorrelation in the presence of each one of the frequent troglobitic species. To do so we employed the Join Count Test of the spdep package (Bivand, Pebesma \& Gómez-Rubio, 2008) and assessed spatial autocorrelation across the full range of spatial scales of our data. The Single Color Statistic was computed for presence-presence in networks of neighboring caves located within increasing distances, until we reached the maximal extent of our study region.

\section{Modeling connectivity between caves}

In order to assess how different landscape features influence the connectivity between caves, we used a landscape genetics approach, whereby a dissimilarity measure was related to landscape resistance to dispersal (Jaffé et al., 2015). Community dissimilarity (Bray-Curtis distance) was used as a proxy for connectivity, assuming that connected caves have more similar troglobitic communities than isolated ones. We then relied on circuit theory (McRae et al. 2008) to estimate landscape resistance to dispersal between caves, considering land cover, elevation, terrain roundedness, and geographic distance.

Because troglobites are obligate subterranean dwellers (Pipan \& Culver, 2013; Culver \& Pipan, 2014), we assumed they can only disperse through the shallow subterranean habitat formed by lateritized igneous mafic rocks and banded ironstone formations (also known as Mountain Savanna or Canga), where our caves are found. We therefore used a 2013 land cover classification map (Souza-Filho et al., 2016) (see Fig. 2) and created a resistance surface to where we attributed low resistance values $(0.1)$ to Canga pixels and high resistance values $(0.9)$ to all other pixels (all other land cover classes). To test whether lower elevations represented higher resistance to troglobite dispersal (given these organisms occur in the highlands), we used a Digital Elevation Model - DEM (SRTM 1 Arc-second global downloaded from https://earthexplorer.usgs.gov/) to build a resistance surface where high elevation pixels represented lower resistance than lowland areas. Additionally, we used the same DEM to create a terrain ruggedness raster using the Terrain Analysis plugin in QGIS V2.14, and test whether pixels with higher roundedness represent higher resistance to troglobitic dispersal. Finally, we created a null-model raster (isolation by geographic distance), where all pixels were coded with identical resistance values (0.5). All rasters were cropped to the extent of the cave locations plus a buffer area of $5 \mathrm{~km}$ to minimize border effects (Jaffé et al., 2015). 
249

250

251

252

253

254

255

256

257

258

distances between all caves, employing all the resistance surfaces described above (land cover, elevation, ruggedness and isolation by geographic distance). Due to Circuitscape's computing limitations we replaced zero values in all rasters with 0.001 , and decreased the resolution of all rasters to achieve reasonable computing times. Finally, we regressed Bray-Curtis dissimilarity distance against resistance distances using Maximum Likelihood Population Effects (MLPE) (Clarke, Rothery \& Raybould, 2002) to account for the non-independence of pairwise distances (Jaffé et al., 2015). Code implementing the MLPE correlation structure within the R package nlme (Pinheiro et al., 2014) is provided at (https://github.com/nspope/corMLPE). Because all resistance distances were highly correlated we only ran simple MLPE models and compared them using the sample size corrected Akaike Information Criterion (AICc).

\section{Results}

The composition of troglobitic communities was influenced by the total subterranean area, cave density, terrain declivity, altitude, lithology, mining and Canga area (Table 1). Specifically, larger mining areas surrounding caves were associated with the occurrence of Paronellidae sp.4, whereas caves surrounded by smaller mining areas were usually inhabited by Charinus carajas and Pyrgodesmidae sp. 1 (Fig. S1). Similarly, caves surrounded by larger Canga areas were associated with Charinus carajas, whereas caves surrounded by smaller areas of Canga usually contained more Systrophiidae sp.1. The relevant scale at which mining and Canga influenced community composition differed, being $250 \mathrm{~m}$ for the former and $50 \mathrm{~m}$ for the later (Fig. 3). Species richness, rarity-weighted richness and phylogenetic diversity were all explained by the distance to the nearest creek, geomorphology, cave area and the presence of guano (Table 1). However, agriculture land cover was found associated to both species richness and phylogenetic diversity, while Canga land cover was an important predictor of rarity-weighted richness. Subterranean area was also found associated to phylogenetic diversity (Table 1). Interestingly, species richness, rarity-weighted richness and phylogenetic diversity increased with increasing distance to the nearest creek, increasing cave area, and the presence of guano. On the other hand, the amount of agricultural landscapes surrounding caves was negatively associated with both species richness and phylogenetic diversity, and in both cases the relevant scale for agriculture land cover was 50m (Fig. 3). Finally, rarity-weighted richness increased with the amount of Canga land cover surrounding caves and the relevant scale for the effect of Canga land cover was $50 \mathrm{~m}$ (Fig. 3). We did not find spatial autocorrelation in any of the model's residuals and no systematic sampling bias effects were detected, given that richness and rarity patterns were not influenced by the cave's proximity to mines (Table S3).

The occurrence of the most frequent species was predicted by cave characteristics, with altitude being the variable determining the presence or absence of most species (Table 2). Presence of guano, cave slope, and presence of water reservoirs were also identified as important predictors of some frequent species, although the direction of these effects varied between species (Table 2).

Species composition, species richness, rarity-weighted richness and phylogenetic diversity were found to be spatially autocorrelated for up to $40 \mathrm{~km}$ (Fig. 4). Above this distance spatial autocorrelation disappeared, revealing a random spatial pattern. The occurrence of frequent troglobitic species was also found to be spatially autocorrelated across spatial scales (Fig. 5). Most troglobitic species were found to be restricted to one or a few caves, but a few were found in more than 100 caves (Fig. 5). 
293

294

295

296

297

298

299

300

301

302

303

304

305

306

307

308

309

310

311

312

313

314

315

316

317

318

319

320

321

322

323

324

325

326

327

328

329

330

331

332

333

334

335

Our connectivity analyses revealed that the model containing geographic distance was the best to explain community dissimilarity, while neither land cover, terrain ruggedness or elevation seemed to influence community dissimilarity (Table 3). Specifically, dissimilarity increased with increasing geographic distance separating caves (Fig. 6).

\section{Discussion}

Relying on spatial statistics to analyze the most comprehensive speleological database yet available for tropical caves, our study reveals the factors underpinning troglobitic community composition, species richness, and phylogenetic diversity. Additionally, we assess patterns of spatial distribution and provide the first insights into the factors influencing the connectivity of troglobitic communities from the Amazon's main source of iron ore.

Species inventories were initially obtained from independent consulting companies, who employed similar sampling methods. These were later validated by specialized taxonomists, and occurrence ranges of rare troglobites were confirmed through further sampling. Since we did not detect any systematic sampling bias effects (Table S3), we are confident that our results reflect the ecology of iron cave troglobites. On the other hand, temporal mismatches between the maps employed to assess landscape features and the timing of speleological surveys could have influenced our analyses. Speleological surveys performed by consulting companies took place between 2005 and 2011 (Serra Norte), between 2010 and 2011 (Serra Leste), and between 2010 and 2011 (Serra Sul; see details in Jaffé et al. 2016). While mining activities in Serra Norte began in the 1980s, long before the speleological surveys took place, Serra Leste had also been exposed to cattle ranching before the speleological surveys were conducted there. Serra Sul, on the other hand, was still completely preserved in 2013 as mining activities had not yet began. Since we calculated landscape metrics using a 2013 land cover map, we believe time-lag effects had a minor impact on our results.

Previous studies have shown that cave size is a key predictor of subterranean biodiversity, because larger caves not only have higher colonization rates, but can also host larger and more diverse communities (Brunet \& Medellín, 2001; Silva, Martins \& Ferreira, 2011; Simões, SouzaSilva \& Ferreira, 2015). In turn, more diverse communities have been found to contain more troglobitic species (Culver et al., 2004; Christman et al., 2005), and a recent study on iron caves found a strong correlation between total species richness and the richness of troglobites (Jaffé et al., 2016). Our results match these previous findings, as habitat amount (assessed through cave area, subterranean area, cave density, and Canga area) was found associated to all response variables (species composition, species richness, rarity-weighted richness, phylogenetic diversity, and the occurrence of some frequent species). Additionally, our results show that proximal habitat amount (Canga within 50m of the caves) is an important predictor of troglobitic community composition and the presence of rare species (Fig. 3). Interestingly, our study is the first one to report an association between the amount of subterranean habitat and phylogenetic diversity, our proxy for functional diversity. This finding suggests that more diverse communities are also more complex and possibly more resilient ones, given the higher functional diversity they harbor (Lean \& Maclaurin, 2016).

Our data also supports the idea that a higher availability of trophic resources facilitates colonization of the cave's interior (Poulson \& White, 1969; Culver \& Pipan, 2009; White \& Culver, 2012; Ferreira, Oliveira \& Silva, 2015), as species richness, rarity-weighted richness and 
336 phylogenetic diversity were higher in caves containing guano. For instance, the cave's deep 337 interior has been compared to a desert since it is largely deprived of trophic resources (White \& 338 Culver, 2012; Pipan \& Culver, 2013). Troglobites thus rely on external material that is washed 339 into the cave or brought in by mobile species (Poulson \& White, 1969; Taylor, Krejca \& Denight, 340 2005; White \& Culver, 2012; Wynne \& Voyles, 2013). Although our findings match those of a 341 recent analysis of 844 iron caves from the Carajás region, which also found higher species 342 richness in caves containing guano (Jaffé et al., 2016), they reveal that this trophic resource not only supports higher species richness but also a higher functional diversity (assessed via phylogenetic diversity). Additionally, our occurrence models reveal that the presence or absence of guano and other feces determines the occurrence of certain frequent species (Table 2), as found for other troglobites (Ferreira \& Martins, 1999; White \& Culver, 2012).

We also identified an effect of cave declivity and slope on species composition, which suggests declivity influences the amount of resources that are carried or washed into caves. Interestingly, species richness, rarity-weighted richness and phylogenetic diversity increased with increasing distances to creeks, indicating a negative effect of water on cave diversity. Supporting these findings, a study of 55 limestone caves from the Brazilian Savannah found that the presence of water bodies significantly influences species composition (Simões, Souza-Silva \& Ferreira, 2015). Similarly, Jaffé et al (2016) found a lower total species richness in caves containing water reservoirs. Although we did not find a general effect of water reservoirs on troglobitic communities, they were found to determine the occurrence of some frequent species (Table 2). Water thus seems to be an important driver of troglobitic biodiversity.

Whereas lithology influenced species composition, geomorphology affected species richness, rarity-weighted richness and phylogenetic diversity. Specifically, the lithology effect was mainly driven by the amount of basic rocks (Fig. S3), while homogeneous or sharp differential geomorphology was the strongest correlate of species richness, rarity-weighted richness and phylogenetic diversity (Fig. S4). Reinforcing our results, a recent study of ten limestone caves found that the amount of limestone outcrops surrounding the caves influence invertebrate community composition (Pellegrini et al., 2016). Likewise, a study of 33 caves from Central Italy revealed that cave morphology and microclimate strongly affected the composition of non-strict cave dwelling organisms (Lunghi, Manenti \& Ficetola, 2014). Finally, a recent landscape genetic study of secret cave cricket populations occurring in 42 limestone caves of central Texas, found a strong influence of karst topography on cricket gene flow (Hutchison et al., 2016). Along with our findings, this accumulated evidence highlights the role of lithology and geomorphology in shaping troglobitic communities.

Elevation was another factor found associated with the species composition of troglobitic communities, with species like Systrophiidae sp.l occurring at higher elevations and species like Charinus carajas occurring at lower ones (Table 1, Fig. S1). Interestingly, altitude was found to be the main variable determining the presence of frequent troglobites, indicating that these species exhibit narrow elevation preferences (elevation ranged from 224 to 842 masl). This result, along with the fact that frequent species responded differently to cave characteristics (Table 2), indicates a high level of specialization, as described for many troglobites (Culver \& Pipan, 2009; Pipan \& Culver, 2013).

To our knowledge, ours is the first study revealing an effect of anthropogenic land use on terrestrial troglobitic communities (Gunn, Hardwick \& Wood, 2000; Wood, Gunn \& Perkins, 380 2002; Moraes, Landis \& Molander, 2002). While mining area within 250m from the caves 
381 influenced species composition, agriculture land cover at the smallest measured scale (50m) had

382 a significant impact on species richness and phylogenetic diversity. Larger mining areas

383 surrounding caves were associated with the occurrence of Paronellidae sp.4, whereas caves

384 containing smaller or no mining areas usually contained Charinus carajas and Pyrgodesmidae

385 sp.1 (Fig. S1). These results suggest that Paronellidae sp.4 is more resilient to mining-led

386 landscape changes than Charinus carajas or Pyrgodesmidae sp.1, which seem more susceptible

387 (these three species occur in 147, 152, and 85 caves respectively, so results are not biased by

388 small sample sizes). However, agriculture but not mining land cover was found associated to

389 species richness and phylogenetic diversity (Table 1). This result was unexpected, given the huge

390 impact of mining on Canga subterranean habitats (Fig. 1), and suggests a role of agricultural

391 practices in the observed decay of species richness and functional diversity. Indeed, herbicides,

392 fungicides, insecticides, fertilizers and mineral salt are widely used in the region, and farmers

393 frequently burn pasturelands (Perz, 2003). As invertebrates have been found among the most

394 affected group by the pesticide doses employed (Schiesari et al., 2013), our findings suggest a

395 role of these compounds in the observed reduction in species richness. Additionally, fire may also

396 influence shallow subterranean environments, and deforestation is likely to reduce the amount of

397 organic material reaching the cave's interior (Beynen \& Townsend, 2005). Finally, land use

398 changes impacting bat populations (i.e. reducing available trophic or roosting resources) are also

399 likely to affect troglobitic communities by depriving them of guano (Muylaert, Stevens \&

400 Ribeiro, 2016).

401 Previous studies have reported spatial autocorrelation in the number of troglobitic species, the 402 number of non-endemics, the number and occurrence frequency of single-cave endemics, the 403 total number of terrestrial species, the presence of troglobites, and the presence of rare troglobites 404 (Christman et al., 2005; Jaffé et al., 2016), which suggests that troglobitic communities are able 405 to influence the troglobitic composition of neighboring caves. Our results match these findings, 406 as troglobitic species composition, species richness, rarity-weighted richness, phylogenetic 407 diversity, and the occurrence of frequent troglobites showed spatial autocorrelation across a range 408 of spatial scales. For instance, the Canga formations where our study caves are found, are 409 constituted by highly porous rocks that form many micro-cavities and cracks (Ferreira, 2005; 410 Silva, Martins \& Ferreira, 2011; Auler et al., 2014). These represent potential subterranean 411 habitats that could serve as dispersal corridors for some troglobitic species (Jaffé et al., 2016), or 412 may actually constitute the primary subterranean habitat of these organisms, with caves being 413 convenient sampling sites (Culver \& Pipan, 2014). Although no study had yet explicitly evaluated 414 connectivity between terrestrial troglobitic communities, there is limited evidence for non415 obligate subterranean dwellers (Pipan \& Culver, 2007; Carlini et al., 2009; Hutchison et al., 416 2016). Here we quantify the influence of landscape resistance on the similarity of terrestrial 417 troglobitic communities, and found that geographic distance is the main factor determining 418 community dissimilarity. Importantly, neither land cover, terrain ruggedness or elevation were 419 found to influence community dissimilarity, indicating that anthropic land uses, rough terrain or 420 elevation gradients may not necessarily represent barriers to subterranean cave connectivity 421 (Christman et al., 2005).

Finally, our study highlights the uniqueness of troglobites, as most troglobitic species were found to be restricted to one or a few caves (Fig. 5). These rare species, restricted to a few caves (35 species occurred in a single cave), represent the most threatened short-range endemics, so they should be conservation priorities. Further actions are nevertheless needed to increase sampling efforts of single-cave endemics, confirm occurrence areas, and validate taxonomic identification. Molecular DNA barcoding tools could contribute increase the accuracy of 
428 taxonomic classification and achieve a fast cross-validation of species occurrences across caves 429 (Juan et al., 2010).

\section{Conclusions}

431 Our results have important implications for the protection of cave biodiversity. First, our findings 432 could guide speleological surveys focus on assessing the most relevant cave characteristics 433 driving troglobitic communities (habitat amount, guano, water, lithology, geomorphology, and 434 elevation). Second, our results highlight the need to regulate agriculture in the vicinity (50m) of 435 iron caves, as agricultural landscapes were found to have a profound impact on troglobitic 436 biodiversity. Third, our work suggests that the conservation of cave clusters should be prioritized, 437 as geographic distance was the main factor determining connectivity between troglobitic 438 communities. Fourth, we argue that conservation efforts should prioritize species occurring in one 439 or a few caves, and underline the need for further actions to confirm occurrence areas and 440 validate taxonomic identification of single-cave endemics. Overall, our work sheds important 441 light onto one of the most overlooked terrestrial ecosystems, and highlights the need to shift 442 conservation efforts from individual caves to subterranean habitats as a whole.

\section{Acknowledgements}

444 We thank Vale's Environmental Licensing and Speleology Department for granting access to its 445 speleology database, and Rafael Melo de Brito for help with GIS analyses.

\section{Supplemental Information}

447 Supplemental figures and tables, Datasets and R scripts. 
448

449

450

451

452

453

454

455

456

457

458

459

460

461

462

463

464

465

466

467

468

469

470

471

472

473

474

475

476

477

478

479

480

481

482

483

\section{References}

Albuquerque F., Beier P. 2015. Rarity-Weighted Richness: A Simple and Reliable Alternative to Integer Programming and Heuristic Algorithms for Minimum Set and Maximum Coverage Problems in Conservation Planning. PLOS ONE 10:e0119905.

Auler AS., Piló LB. 2015. Caves and mining in Brazil: The dilemma of cave preservation within a mining context. In: Andreo B, Carrasco F, Durán JJ, Jiménez P, LaMoreaux JW eds. Environmental Earth Sciences. Environmental Earth Sciences. Springer Berlin Heidelberg, 487-496. DOI: 10.1007/978-3-642-17435-3_55.

Auler A., Piló L., Parker C., Senko J., Sasowsky I., Barton H. 2014. Hypogene cave patterns in iron ore caves: Convergence of forms or processes? In: Klimchouk A, Sasowsky ID, Mylroie J, Engel SA, Engel AS eds. Hypogene Cave Morphologies. Leesburg, Virginia: Karst Water Institute, 15-19.

Bates D., Maechler M., Bolker B., Walker S. 2014. lme4: Linear mixed-effects models using Eigen and S4.

Beynen P., Townsend K. 2005. A Disturbance Index for Karst Environments. Environmental Management 36:101-116. DOI: 10.1007/s00267-004-0265-9.

Bivand RS., Pebesma EJ., Gómez-Rubio V. 2008. Applied Spatial Data Analysis with R. Springer-Verlag New York.

Bivand R., Piras G. 2015. Comparing implementations of estimation methods for spatial econometrics. In: American Statistical Association,.

Brunet AK., Medellín RA. 2001. The species-area relationship in bat assemblages of tropical caves. Journal of Mammalogy 82:1114-1122.

Carlini DB., Manning J., Sullivan PG., Fong DW. 2009. Molecular genetic variation and population structure in morphologically differentiated cave and surface populations of the freshwater amphipod Gammarus minus. Molecular Ecology 18:1932-1945. DOI: 10.1111/j.1365-294X.2009.04161.x.

Christman MC., Culver DC., Madden MK., White D. 2005. Patterns of endemism of the eastern North American cave fauna. Journal of Biogeography 32:1441-1452. DOI: 10.1111/j.13652699.2005.01263.x.

Christman MC., Doctor DH., Niemiller ML., Weary DJ., Young JA., Zigler KS., Culver DC. 2016. Predicting the Occurrence of Cave-Inhabiting Fauna Based on Features of the Earth Surface Environment. PLOS ONE 11:e0160408.

Clarke RT., Rothery P., Raybould AF. 2002. Confidence limits for regression relationships between distance matrices: estimating gene flow with distance. Journal of agricultural, biological, and environmental statistics 7:361-372.

Culver DC., Christman MC., Šereg I., Trontelj P., Sket B. 2004. The location of terrestrial 
species-rich caves in a cave-rich area. Subterranean Biology 2:27-32.

485

486

487 488

489

490

491

492

493

494

495

496

497

498

499

500

501

502

503

504

505

506

507

508

509

510

511

512

513

514

515

516

517

518

Culver DC., Pipan T. 2009. The biology of caves and other subterranean habitats. Oxford University Press, USA.

Culver DC., Pipan T. 2014. Shallow subterranean habitats: ecology, evolution, and conservation. Oxford University Press, USA.

Faith DP. 2015. Phylogenetic diversity, functional trait diversity and extinction: avoiding tipping points and worst-case losses. Philosophical transactions of the Royal Society of London. Series B, Biological sciences 370:200140011. DOI: 10.1098/rstb.2014.0011.

Ferreira RL. 2005. A vida subterrânea nos campos ferruginosos. O carste 3:106-115.

Ferreira RL., Martins RP. 1999. Trophic structure and natural history of bat guano invertebrate communities, with special reference to Brazilian caves. Tropical zoology 12:231-252.

Ferreira RL., Oliveira MPA., Silva MS. 2015. Biodiversidade subterrânea em geossistemas ferruginosos. In: Geossistemas ferruginosos do Brasil: Áreas prioritárias para conservação da diversiadde geológica e biológica, patrimônio cultural e serviços ambientais. Belo Horizonte, MG: Instituto Prístino, 195-231.

Flynn DFB., Mirotchnick N., Jain M., Palmer MI., Naeem S. 2011. Functional and phylogenetic diversity as predictors of biodiversity-ecosystem $\square$ function relationships. Ecology 92:15731581 .

Gunn J., Hardwick P., Wood PJ. 2000. The invertebrate community of the Peak-Speedwell cave system, Derbyshire, England - pressures and considerations for conservation management. Aquatic Conservation: Marine and Freshwater Ecosystems 10:353-369. DOI: 10.1002/1099-0755(200009/10)10:5<353::AID-AQC413>3.0.CO;2-S.

Guzik MT., Austin AD., Cooper SJB., Harvey MS., Humphreys WF., Bradford T., Eberhard SM., King RA., Leys R., Muirhead KA. 2011. VIEWPOINT. Is the Australian subterranean fauna uniquely diverse? Invertebrate Systematics 24:407-418.

Harvey MS. 2002. Short-range endemism among the Australian fauna: Some examples from nonmarine environments. Invertebrate Systematics 16:555-570. DOI: 10.1071/IS02009.

Harvey MS., Rix MG., Framenau VW., Hamilton ZR., Johnson MS., Teale RJ., Humphreys G., Humphreys WF. 2011. Protecting the innocent: Studying short-range endemic taxa enhances conservation outcomes. Invertebrate Systematics 25:1-10. DOI: 10.1071/IS11011.

Hedges SB., Kumar S. 2009. The timetree of life. OUP Oxford.

Hedges SB., Marin J., Suleski M., Paymer M., Kumar S. 2015. Tree of life reveals clock-like speciation and diversification. Molecular Biology and Evolution 32:835-845. DOI: 10.1093/molbev/msv037.

Hutchison NL., Lance RF., Pekins CE., Noble ME., Leberg PL. 2016. Influence of 
519 geomorphology and surface features on the genetic structure of an important trogloxene, the secret cave cricket (Ceuthophilus secretus). Conservation Genetics:1-15.

521

522

523

524

525

526

527

528

529

530

531

532

533

534

535

536

537

538

539

540

541

542

543

544

545

546

547

548

549

550

551

552

553

Jaffé R., Castilla A., Pope N., Imperatriz-Fonseca VL., Metzger JP., Arias MC., Jha S. 2015. Landscape genetics of a tropical rescue pollinator. Conservation Genetics 17:267-278. DOI: 10.1007/s10592-015-0779-0.

Jaffé R., Prous X., Zampaulo R., Giannini T., Imperatriz-Fonseca V., Maurity C., Oliveira G., Brandi I., Siqueira J. 2016. Reconciling mining with the conservation of cave biodiversity: A quantitative baseline to help establish conservation priorities. PloSOne 11:e0168348. DOI: 10.1371/journal. pone.0168348.

Juan C., Guzik MT., Jaume D., Cooper SJB. 2010. Evolution in caves: Darwin's “wrecks of ancient life" in the molecular era. Molecular Ecology 19:3865-3880. DOI: 10.1111/j.1365294X.2010.04759.x.

Lean C., Maclaurin J. 2016. The value of phylogenetic diversity. In: Biodiversity Conservation and Phylogenetic Systematics. Springer, 19-37.

Lunghi E., Manenti R., Ficetola GF. 2014. Do cave features affect underground habitat exploitation by non-troglobite species? Acta Oecologica 55:29-35. DOI: http://dx.doi.org/10.1016/j.actao.2013.11.003.

McRae BH. 2006. Isolation by resistance. Evolution 60:1551-1561. DOI: 10.1111/j.00143820.2006.tb00500.x.

Moraes R., Landis WG., Molander S. 2002. Regional Risk Assessment of a Brazilian Rain Forest Reserve. Human and Ecological Risk Assessment: An International Journal 8:1779-1803. DOI: $10.1080 / 20028091057600$.

Muylaert RL., Stevens RD., Ribeiro MC. 2016. Threshold effect of habitat loss on bat richness in cerrado-forest landscapes. Ecological Applications 26:1854-1867. DOI: 10.1890/15-1757.1.

Oksanen J., Blanchet FG., Friendly M., Kindt R., Legendre P., McGlinn D., Minchin PR., O’Hara RB., Simpson GL., Solymos P., Stevens MHH., Szoecs E., Wagner H. 2016. vegan: Community Ecology Package.

Pellegrini T., Sales LP., Aguiar P., Lopes Ferreira R. 2016. Linking spatial scale dependence of land-use descriptors and invertebrate cave community composition. Subterranean Biology 18:17-38. DOI: 10.3897/subtbiol.18.8335.

Perz SG. 2003. Social Determinants and Land Use Correlates of Agricultural Technology Adoption in a Forest Frontier : A Case Study in the Brazilian Amazon. Human Ecology 31:133-165.

Pinheiro J., Bates D., DebRoy S., Sarkar D. 2014. nlme: Linear and Nonlinear Mixed Effects Models. 
554 Pipan T., Culver DC. 2007. Copepod distribution as an indicator of epikarst system connectivity.

555 Hydrogeology Journal 15:817-822. DOI: 10.1007/s10040-006-0114-4.

556 Pipan T., Culver D. C. 2013. Subterranean Ecosystems. In: Levin SA ed. Encyclopedia of

557 Biodiversity. Waltham, MA: Academic Press., 44-62. DOI: 10.1016/B0-12-226865-

$558 \quad 2 / 00262-5$.

559 Poulson TL., White WB. 1969. The Cave Environment. Science 165:971-981.

560 Poveromo JJ. 1999. Iron Ores. In: The Making, Shaping, and Treating of Steel: Ironmaking 561 volume. Pittsburg, PA: The AISE Steel Foundation, 547-550.

562 R Core T. 2015. R: A language and environment for statistical computing.

563 Schiesari L., Waichman A., Brock T., Adams C., Grillitsch B. 2013. Pesticide use and biodiversity 564 conservation in the Amazonian agricultural frontier. Philosophical transactions of the Royal $565 \quad$ Society of London. Series B, Biological sciences 368:20120378. DOI:

$566 \quad 10.1098 /$ rstb.2012.0378.

567 Silva MS., Martins RP., Ferreira RL. 2011. Cave lithology determining the structure of the 568 invertebrate communities in the Brazilian Atlantic Rain Forest. Biodiversity and $569 \quad$ Conservation 20:1713-1729.

570 Simões MH., Souza-Silva M., Ferreira RL. 2015. Cave physical attributes influencing the 571 structure of terrestrial invertebrate communities in Neotropics. Subterranean Biology $572 \quad 16: 103$.

573 Souza-Filho PWM., de Souza EB., Silva Júnior RO., Nascimento WR., Versiani de Mendonça 574 BR., Guimarães JTF., Dall'Agnol R., Siqueira JO. 2016. Four decades of land-cover, land575 use and hydroclimatology changes in the Itacaiúnas River watershed, southeastern Amazon.

576 Journal of Environmental Management 167:175-184. DOI: 10.1016/j.jenvman.2015.11.039.

577 Taylor SJ., Krejca JK., Denight ML. 2005. Foraging Range and Habitat Use of Ceuthophilus 578 secretus (Orthoptera: Rhaphidophoridae), a Key Trogloxene in Central Texas Cave 579 Communities. The American Midland Naturalist 154:97-114. DOI: 10.1674/0003$580 \quad$ 0031(2005)154[0097:FRAHUO]2.0.CO;2.

581 Trajano E., Bichuette ME. 2010. Relevância de cavernas: porque estudos ambientais 582 espeleobiológicos não funcionam. Espeleo-Tema 21:105-112.

583 Webb CO., Ackerly DD., McPeek M a., Donoghue MJ. 2002. Phylogenies and Community 584 Ecology. Annual Review of Ecology and Systematics 33:475-505. DOI:

$585 \quad$ 10.1146/annurev.ecolsys.33.010802.150448.

586 White WB., Culver DC. 2012. Encyclopedia of caves. Academic Press.

587 Wood PJ., Gunn J., Perkins J. 2002. The impact of pollution on aquatic invertebrates within a 588 subterranean ecosystem-out of sight out of mind. 
589 Wynne JJ., Voyles KD. 2013. Cave-dwelling arthropods and vertebrates of North Rim Grand

590 Canyon, with notes on ecology and management. Western North American Naturalist 74:1-17. 


\section{Table $\mathbf{1}$ (on next page)}

Summary of the best models describing troglobitic species composition, species richness and phylogenetic diversity. 
1 Table 1: Summary of the best models describing troglobitic species composition, species

2 richness, rarity-weighted richness and phylogenetic diversity.

\begin{tabular}{|c|c|c|c|c|c|c|}
\hline Response variable & Model $^{\text {a }}$ & Predictor variables & Estimate & SE & $\mathbf{t} / \mathbf{z}$ & p \\
\hline \multirow{3}{*}{$\begin{array}{l}\text { Species composition } \\
\text { (MDS1) }\end{array}$} & \multirow{3}{*}{ LMM } & Subterranean area $(500 \mathrm{~m})$ & 0.13 & 0.04 & 3.12 & 0.002 \\
\hline & & Declivity $0-10^{\circ}(500 \mathrm{~m})$ & 0.09 & 0.03 & 2.98 & 0.003 \\
\hline & & Mining area $(250 \mathrm{~m})$ & -0.08 & 0.03 & -3.01 & 0.003 \\
\hline \multirow{5}{*}{$\begin{array}{l}\text { Species composition } \\
(\mathrm{MDS} 2)\end{array}$} & \multirow{5}{*}{ LMM } & Declivity $30-40^{\circ}(500 \mathrm{~m})$ & -0.06 & 0.02 & -2.74 & 0.006 \\
\hline & & Cave density (50m) & -0.08 & 0.02 & -3.23 & 0.001 \\
\hline & & Lithology axis $2(50 \mathrm{~m})$ & -0.10 & 0.04 & -2.51 & 0.012 \\
\hline & & Canga area $(50 \mathrm{~m})$ & 0.07 & 0.03 & 2.44 & 0.015 \\
\hline & & Altitude & -0.06 & 0.03 & -1.82 & 0.070 \\
\hline \multirow{5}{*}{ Species richness } & \multirow{5}{*}{ GLMM } & Distance to nearest creek & 0.13 & 0.04 & 3.04 & 0.002 \\
\hline & & Geomorphology axis $2(50 \mathrm{~m})$ & 0.20 & 0.05 & 3.85 & $<0.001$ \\
\hline & & Agriculture area $(50 \mathrm{~m})$ & -0.15 & 0.04 & -4.29 & $<0.001$ \\
\hline & & Cave area & 0.30 & 0.03 & 10.11 & $<0.001$ \\
\hline & & Presence of guano & 0.35 & 0.07 & 5.33 & $<0.001$ \\
\hline \multirow{5}{*}{$\begin{array}{l}\text { Rarity-weighted } \\
\text { richness } \\
\text { (log-transformed) }\end{array}$} & \multirow{5}{*}{ LMM } & Distance to nearest creek & 0.28 & 0.1 & 2.87 & 0 \\
\hline & & Geomorphology axis $2(50 \mathrm{~m})$ & 0.27 & 0.11 & 2.56 & 0.01 \\
\hline & & Canga area $(50 \mathrm{~m})$ & 0.25 & 0.08 & 3.34 & $<0.001$ \\
\hline & & Cave area & 0.5 & 0.07 & 7.55 & $<0.001$ \\
\hline & & Presence of guano & 0.54 & 0.14 & 3.89 & $<0.001$ \\
\hline \multirow{6}{*}{ Phylogenetic diversity } & \multirow{6}{*}{ LMM } & Distance to nearest creek & 176.25 & 64.69 & 2.72 & 0.007 \\
\hline & & Subterranean area $(50 \mathrm{~m})$ & 125.46 & 49.04 & 2.56 & 0.011 \\
\hline & & Geomorphology axis $2(50 \mathrm{~m})$ & 180.44 & 71.08 & 2.54 & 0.012 \\
\hline & & Agriculture area $(50 \mathrm{~m})$ & -203.45 & 51.50 & -3.95 & $<0.001$ \\
\hline & & Cave area & 551.18 & 53.99 & 10.21 & $<0.001$ \\
\hline & & Presence of guano & 390.94 & 93.70 & 4.17 & $<0.001$ \\
\hline
\end{tabular}

Response variables are shown followed by the type of model employed (Model), the predictor variables included in the best models (selected through likelihood ratio tests with $\alpha<0.05$ ), estimates, standard errors (SE), $t / z$ values and $p$-values. ${ }^{a}$ Linear mixed models (LMM) or Generalized Linear Mixed Models (GLMM). All models accounted for spatial autocorrelation and unaccounted variation between study sites by keeping the highland were the caves were located as a random effect. Eight out of the 473 caves were excluded from these analyses because they contained missing data in at least one field. 


\section{Table 2 (on next page)}

Parameter estimates for the best models explaining the presence of the most frequent troglobitic species (occurring in at least 30 caves). 
1 Table 2: Parameter estimates for the best models explaining the presence of the most frequent

2 troglobitic species (occurring in at least 30 caves).

\begin{tabular}{|l|l|l|l|l|l|l|}
\hline Species & Altitude & $\begin{array}{l}\text { Presence of } \\
\text { guano }\end{array}$ & Cave slope & $\begin{array}{l}\text { Presence } \\
\text { of water } \\
\text { reservoirs }\end{array}$ & $\begin{array}{l}\text { Presence } \\
\text { of other } \\
\text { feces }\end{array}$ & Cave area \\
\hline aff Xyccarph sp1 & -0.003 & -0.947 & & & & \\
\hline Carajas paraua & & & 0.136 & 0.642 & & \\
\hline Charinus carajas & -0.002 & & 0.107 & & 0.331 & \\
\hline Charinus orientalis & -0.004 & 1.230 & -0.164 & & & \\
\hline Circoniscus buckupi & 0.003 & & & -1.192 & 1.600 & \\
\hline Cyphoderidae sp1 & & 1.106 & & & & \\
\hline Cyphoderidae sp2 & & 1.753 & & & & 0.001 \\
\hline Entomobryidae sp4 & 0.007 & & & & & \\
\hline Entomobryomorpha sp & -0.004 & & 0.156 & 1.172 & -1.316 & \\
\hline Isotomidae sp2 & -0.003 & & 0.102 & 1.035 & & \\
\hline Matta sp1 & 0.009 & & 0.104 & & & \\
\hline Paronellidae sp4 & 0.006 & 0.708 & & & & \\
\hline Pyrgodesmidae sp1 & -0.004 & -0.900 & 0.159 & 1.341 & -0.833 & \\
\hline Systrophiidae sp1 & -0.010 & 1.705 & & -1.672 & & \\
\hline $\begin{array}{l}\text { Total number of } \\
\text { models }\end{array}$ & $\mathbf{1 1}$ & $\mathbf{7}$ & $\mathbf{7}$ & $\mathbf{6}$ & $\mathbf{4}$ & $\mathbf{2}$ \\
\hline
\end{tabular}


Table 3(on next page)

Comparison of connectivity models. 
1 Table 3: Comparison of connectivity models.

\begin{tabular}{|l|l|l|l|l|}
\hline Predictors variable & Log-likelihood & AICc & $\Delta$ AICc & weight \\
\hline Geographic distance & 41538.18 & -83068.35 & 0.00 & 1.00 \\
\hline Land cover & 41392.50 & -82777.00 & 291.35 & 0.00 \\
\hline Rougedness & 41352.66 & -82697.32 & 371.04 & 0.00 \\
\hline Elevation & 40989.58 & -81971.17 & 1097.18 & 0.00 \\
\hline
\end{tabular}




\section{Figure 1}

Iron ore mine (N5, Serra Norte, Carajás, Brazil) showing the location of caves colored by their relevance classification.

The photo shows how mine planning is affected by the occurrence of maximum relevance caves, which must be protected along with a $250 \mathrm{~m}$ radius. Cave data was retrieved from Jaffé et al. (2016), while the image was provided by Google Imagery 2017. Coordinates are shown in decimal degrees.

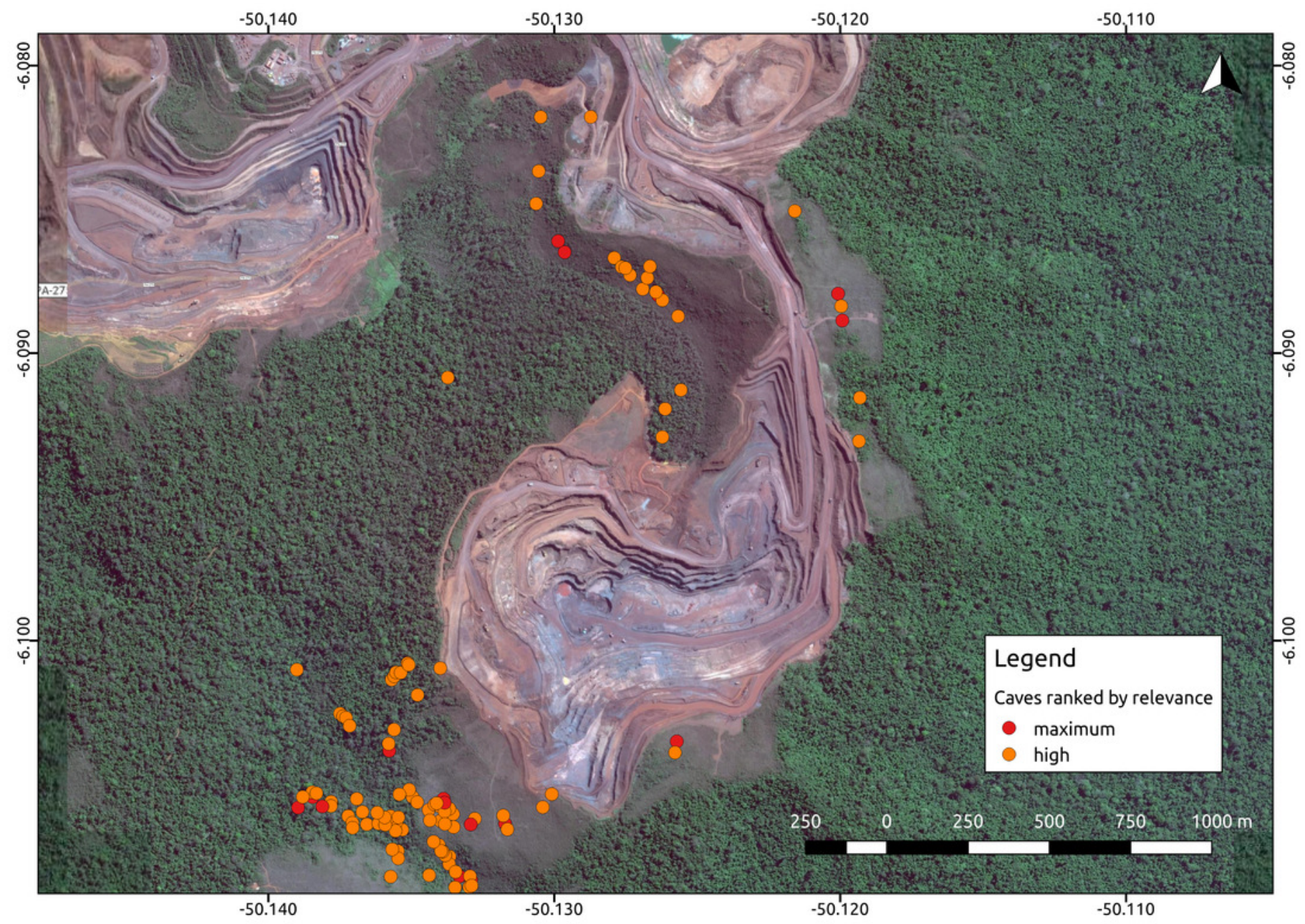




\section{Figure 2}

Location of the study region (upper left corner) and a detail of the study area showing the spatial distribution of the caves included in our analyses (white dots, $N=473$ ) over elevation and a land cover layers.

While the digital elevation raster (SRTM, 1 arc-second) was obtained from USGS Earth Explorer, the land use classification shapefile was obtained from Souza-Filho et al. (2016). Coordinates are shown in decimal degrees.

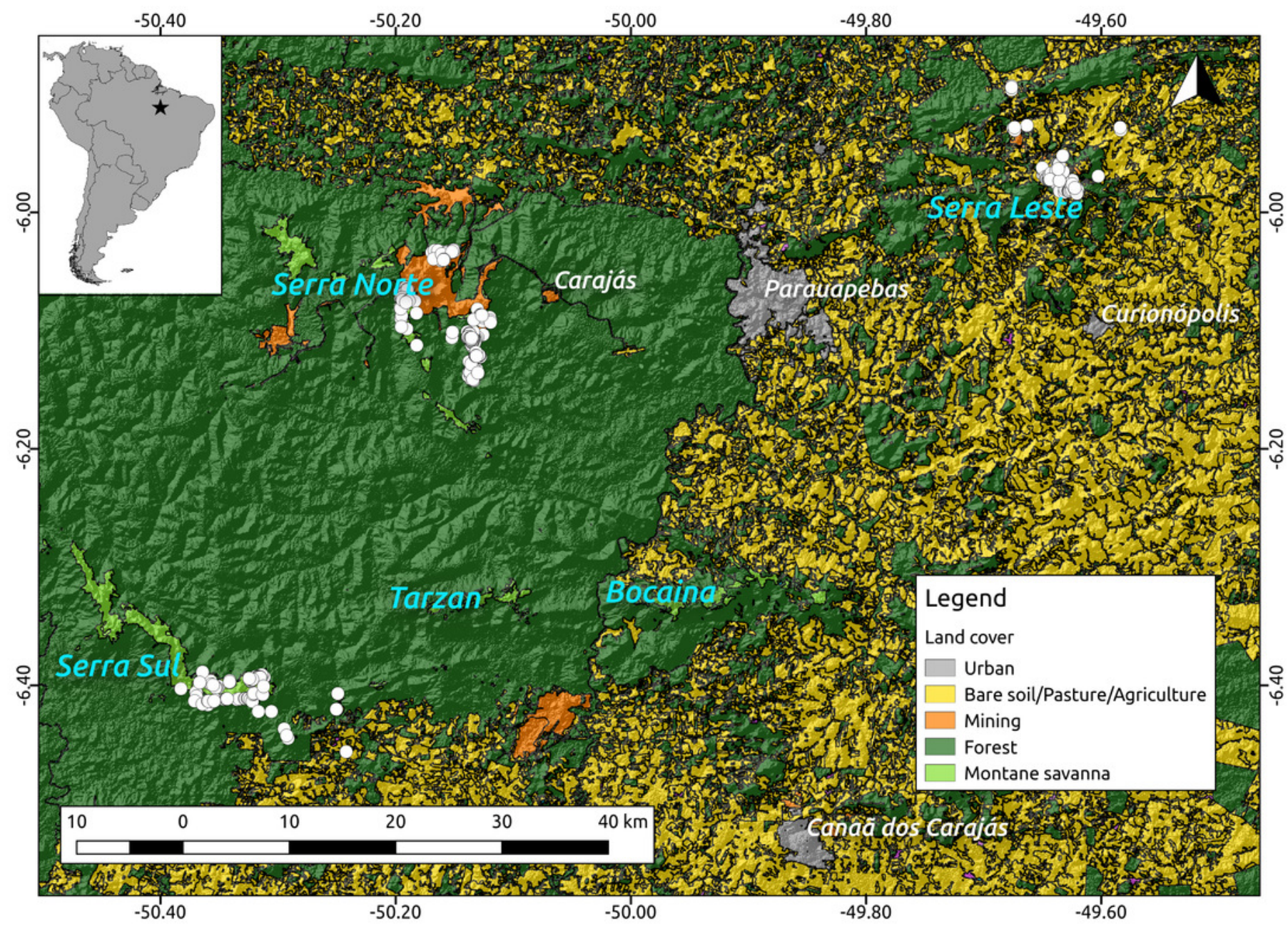




\section{Figure 3}

Influence of land cover on troglobitic species composition, species richness, rarityweighted richness and phylogenetic diversity across spatial scales.

The $\mathrm{Y}$ axis show the Akaike Information Criteria (AIC) of simple mixed models containing each land cover predictor at four different spatial scales. Lowest AIC values indicate the scale at which each predictor best explained response variables. 

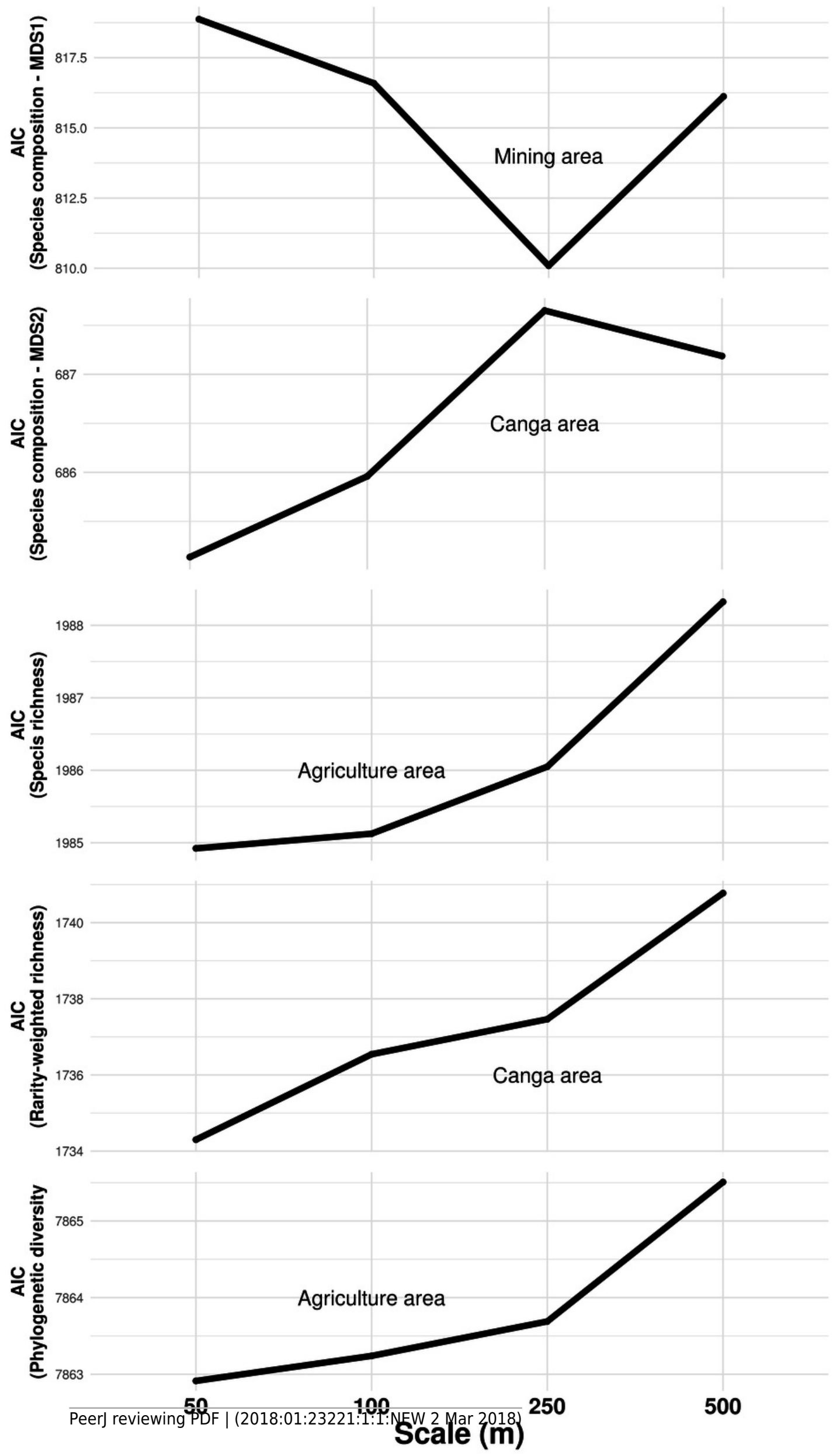


\section{Figure 4}

Spatial autocorrelation of troglobitic species composition, species richness, rarityweighted richness and phylogenetic diversity across different spatial scales.

While the solid lines show the value of Moran's I estimates, the gray area depict $95 \%$ confidence intervals. The dashed line represent expected values under a null model of no spatial autocorrelation. 

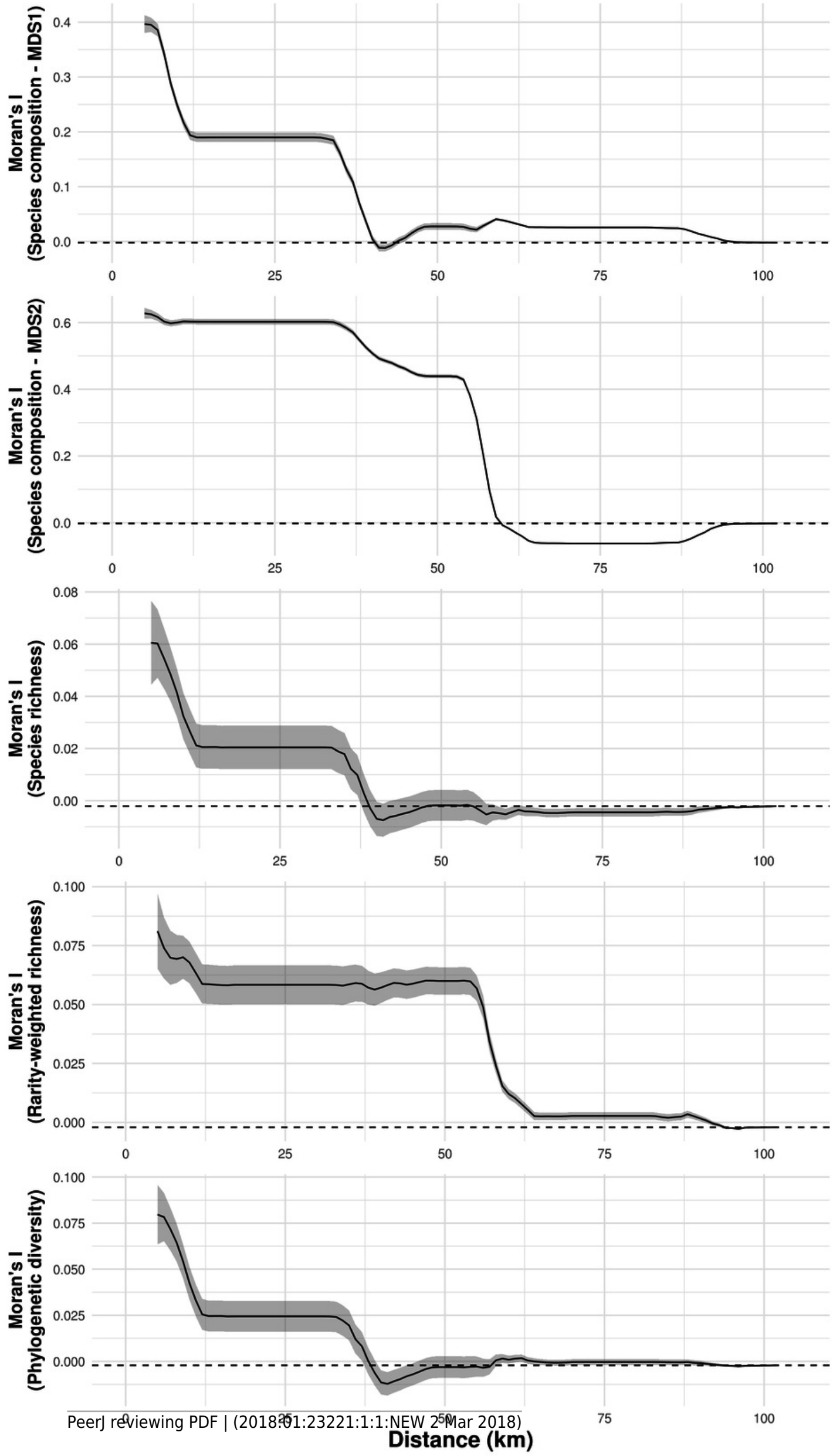


\section{Figure 5}

Spatial autocorrelation in the occurrence of the most frequent troglobitic species (occurring in 30 or more caves) across different spatial scales (A-N), and frequency distribution of occurrences by species (0).

Solid lines in A-N show the value of Single Color Statistic estimates, gray area depict 95\% confidence intervals, and dashed lines represent expected values under a null model of no spatial autocorrelation. The dashed vertical line in 0 shows the threshold value of species occurring in at least 30 caves. 

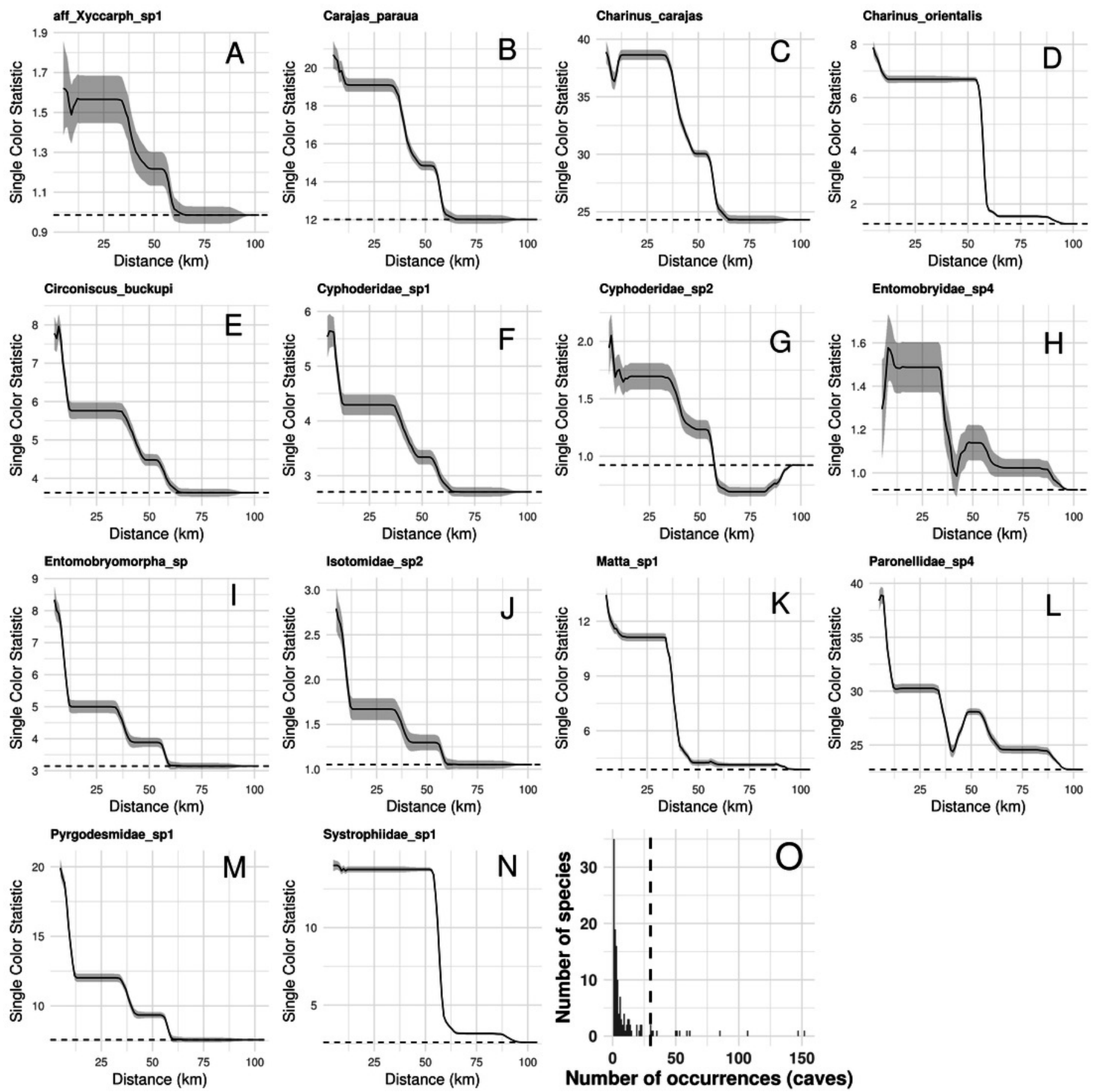
Figure 6

Relationship between troglobitic community dissimilarity (Bray-Curtis distance) and geographic distance resistance distance.

Dissimilarity distance is de-correlated for the MLPE correlation structure.

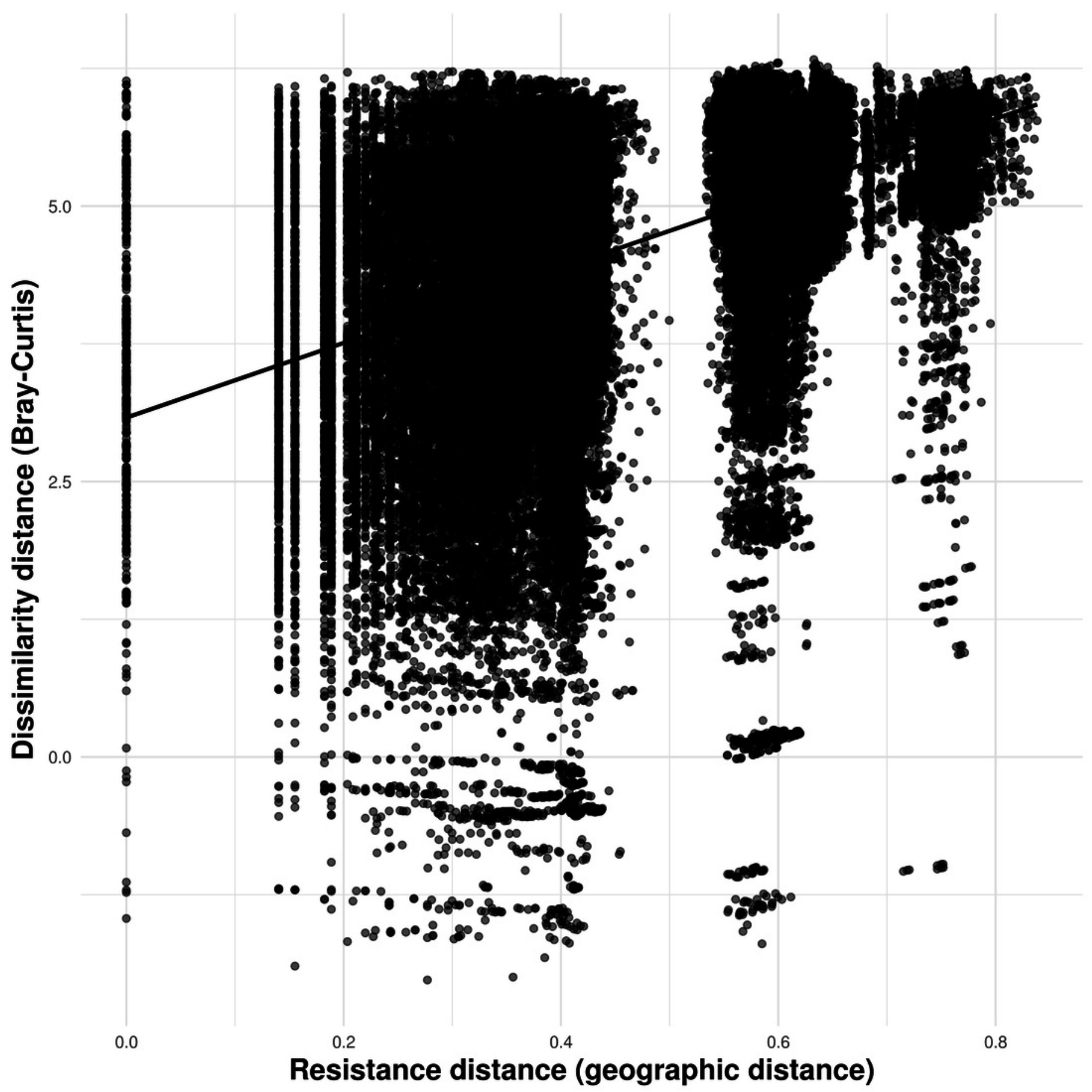

